\title{
Standardized Entrance Assessment in Kindergarten: A Qualitative Analysis of the Experiences of Teachers, Administrators, and Parents
}

\author{
Martha T. Dever \\ James J. Barta \\ Utah State University
}

\begin{abstract}
To assist early childhood educators in responding to mandated standardized assessment, the purpose of this qualitative inquiry was to acquire an indepth understanding of the experiences of teachers, parents, and administrators in relation to two stated purposes of the assessment: assistance for planning curriculum, and providing information for parents to support literacy learning at home. This study resulted in grounded theory about the strengths and weaknesses of standardized testing in kindergarten. In sum, the strengths that emerged from these data include: a) some immediate information at a glance; b) consistency of information with the core curriculum and across districts; c) time and opportunity for one-on-one interaction among teachers, parents, and children; d) time and opportunity to begin parent and teacher dialogue; and e) ease of the first day of school. The weaknesses that emerged from these data include: a) the narrow scope of information gleaned; $b$ ) lack of validity of the results; $c$ ) the potential for placing undue importance on the assessment, resulting in inappropriate practice; d) limited changes in the curriculum;e) misuse of instructional time; and f) anxiety for teachers, parents, and children.
\end{abstract}

Increasingly, various standardized and aptitude tests have become an integral part of schools. Prior to 1950, high school graduates completed an average of three standardized tests in their school careers; students graduating in 1989 might have completed as many as 21 (Perrone, 1990). Increased federal and state resources for schools in the 1960s and the accountability movement of the 1970s further increased the use of various tests across curriculum areas. Recently, such tests have become tools for selection and retention, and their use has expanded to include the early years in order to address issues such as readiness to enter kindergarten or 1st grade and tracking (Perrone, 1990).

The National Education Goals Panel (Shepard, Kagan, \& Wurtz, 1998) notes that tests administered to children under the age of 8 lack validity and reliability. In addition, due to their rapid rates of growth and development, individual children may have changed significantly by the time test results are aggregated and reported. Thus, the tests have limited value for curriculum planning.

During the 1997 legislative session, Utah legislators approved State Bill 53A.3-402.9, which mandates standardized assessment of emerging early reading and numeric skills for children entering kindergarten. As a result, the Utah State Office of Education and school districts cooperatively developed a standardized entrance assessment instrument. Districts are required to report results to the state office. The primary intent of the assessment is to provide kindergarten teachers with the information they need to develop curriculum, and to share with parents, who will use it to support their children's literacy learning at home. It is also intended to guide the development of state-wide teacher inservice and preschool literacy programs.

Assessment to inform instructional plan- 
ning and identify delays in children's literacy development is supported by early childhood teachers and researchers. Even though the state should be commended for its focus on young children and their families, standardized assessment is not the best tool to meet these objectives. By definition, standardized assessments are administered identically to each child and thus are hinged on inappropriate practice. Teachers are denied the flexibility to address the various developmental, individual, and cultural needs of children in their classrooms. Appropriate practice is further threatened by reporting the results to the state office of education, which heightens the potential for high-stakes testing.

Ongoing, performance-based assessment provides valid information that cannot be garnered from a single standardized assessment. Early childhood professionals advocate the need for assessing young children by using multiple measures over time and in the context of daily classroom activities. This enables teachers to adjust instruction from day to day to meet the changing needs of individual children in their classrooms.

The position on this issue is certainly not new. Theory and research (Burts, Hart, Charlesworth, \& Kirk, 1990; Fleege, Charlesworth, Burts, \& Hart, 1993; Kamii \& Kamii, 1990; Wodtke, Harper, Schommer, $\&$ Brunelli, 1989) suggest that the use of standardized tests may harm young children. For years, early childhood scholars and researchers have advocated for performance-based assessment, rather than standardized measures, for instructional planning purposes. However, despite what we have learned about developmentally appropriate assessment, some inappropriate practices continue.

Of the 46 states responding to our query, nine (Alabama, Georgia, Florida, Louisiana, North Dakota, Nevada, South Carolina, Utah, and West Virginia) have a legislative mandate to administer some type of entrance assessment in kindergarten; a tenth (Oklahoma) mandates an assessment be administered during kindergarten. Specific mandates vary among the 10 states. Five states (Alabama, Georgia, South Carolina, Utah, and West Virginia) mandate the use of a specific standardized instrument (which varies among the five) and, with the exception of West Virginia, require that results be reported to the state office of education. The other states allow districts the flexibility to select the assessment instrument, and most do not require results to be reported. Some states consider entrance test results along with other data for placement decisions, but none advocate the use of results as the sole determinant for placement in kindergarten or promotion to 1st grade.

The purpose of this qualitative inquiry is to add to the literature a rich understanding of the experiences of teachers, parents, and administrators regarding two stated purposes of the standardized kindergarten entrance assessment: a) offering assistance for planning the curriculum, and $b$ ) providing information for parents to support literacy learning at home. The specific research question asked was: What are the perspectives of teachers, parents, and administrators concerning the use of standardized assessment for planning curriculum and literacy experiences at home?

Existing research (Burts et al., 1990; Fleege et al., 1993; Wodtke et al., 1989) is primarily quantitative, providing group data regarding the phenomenon of standardized testing of young children. This qualitative study enriches the literature by illuminating the multiple perspectives of the adult stakeholders (teachers, parents, and administrators) regarding the kindergarten assessment.

\section{Mandating Kindergarten \\ Entrance Assessment in Utah}

The mandated, statewide assessment in Utah was voted into law at the 1997 legislative session. Feeling that whatever teachers were doing "wasn't working," the bill's author proposed that a statewide assessment be developed and implemented in all kindergarten classrooms. The legislator's objective was to identify and address the 
ning and identify delays in children's literacy development is supported by early childhood teachers and researchers. Even though the state should be commended for its focus on young children and their families, standardized assessment is not the best tool to meet these objectives. By definition, standardized assessments are administered identically to each child and thus are hinged on inappropriate practice. Teachers are denied the flexibility to address the various developmental, individual, and cultural needs of children in their classrooms. Appropriate practice is further threatened by reporting the results to the state office of education, which heightens the potential for high-stakes testing.

Ongoing, performance-based assessment provides valid information that cannot be garnered from a single standardized assessment. Early childhood professionals advocate the need for assessing young children by using multiple measures over time and in the context of daily classroom activities. This enables teachers to adjust instruction from day to day to meet the changing needs of individual children in their classrooms.

The position on this issue is certainly not new. Theory and research (Burts, Hart, Charlesworth, \& Kirk, 1990; Fleege, Charlesworth, Burts, \& Hart, 1993; Kamii \& Kamii, 1990; Wodtke, Harper, Schommer, \& Brunelli, 1989) suggest that the use of standardized tests may harm young children. For years, early childhood scholars and researchers have advocated for performance-based assessment, rather than standardized measures, for instructional planning purposes. However, despite what we have learned about developmentally appropriate assessment, some inappropriate practices continue.

Of the 46 states responding to our query, nine (Alabama, Georgia, Florida, Louisiana, North Dakota, Nevada, South Carolina, Utah, and West Virginia) have a legislative mandate to administer some type of entrance assessment in kindergarten; a tenth (Oklahoma) mandates an assessment be administered during kindergarten. Specific mandates vary among the 10 states. Five states (Alabama, Georgia, South Carolina, Utah, and West Virginia) mandate the use of a specific standardized instrument (which varies among the five) and, with the exception of West Virginia, require that results be reported to the state office of education. The other states allow districts the flexibility to select the assessment instrument, and most do not require results to be reported. Some states consider entrance test results along with other data for placement decisions, but none advocate the use of results as the sole determinant for placement in kindergarten or promotion to 1st grade.

The purpose of this qualitative inquiry is to add to the literature a rich understanding of the experiences of teachers, parents, and administrators regarding two stated purposes of the standardized kindergarten entrance assessment: a) offering assistance for planning the curriculum, and $b$ ) providing information for parents to support literacy learning at home. The specific research question asked was: What are the perspectives of teachers, parents, and administrators concerning the use of standardized assessment for planning curriculum and literacy experiences at home?

Existing research (Burts et al., 1990; Fleege et al., 1993; Wodtke et al., 1989) is primarily quantitative, providing group data regarding the phenomenon of standardized testing of young children. This qualitative study enriches the literature by illuminating the multiple perspectives of the adult stakeholders (teachers, parents, and administrators) regarding the kindergarten assessment.

\section{Mandating Kindergarten}

Entrance Assessment in Utah

The mandated, statewide assessment in Utah was voted into law at the 1997 legislative session. Feeling that whatever teachers were doing "wasn't working," the bill's author proposed that a statewide assessment be developed and implemented in all kindergarten classrooms. The legislator's objective was to identify and address the 
ning and identify delays in children's literacy development is supported by early childhood teachers and researchers. Even though the state should be commended for its focus on young children and their families, standardized assessment is not the best tool to meet these objectives. By definition, standardized assessments are administered identically to each child and thus are hinged on inappropriate practice. Teachers are denied the flexibility to address the various developmental, individual, and cultural needs of children in their classrooms. Appropriate practice is further threatened by reporting the results to the state office of education, which heightens the potential for high-stakes testing.

Ongoing, performance-based assessment provides valid information that cannot be garnered from a single standardized assessment. Early childhood professionals advocate the need for assessing young children by using multiple measures over time and in the context of daily classroom activities. This enables teachers to adjust instruction from day to day to meet the changing needs of individual children in their classrooms.

The position on this issue is certainly not new. Theory and research (Burts, Hart, Charlesworth, \& Kirk, 1990; Fleege, Charlesworth, Burts, \& Hart, 1993; Kamii \& Kamii, 1990; Wodtke, Harper, Schommer, \& Brunelli, 1989) suggest that the use of standardized tests may harm young children. For years, early childhood scholars and researchers have advocated for performance-based assessment, rather than standardized measures, for instructional planning purposes. However, despite what we have learned about developmentally appropriate assessment, some inappropriate practices continue.

Of the 46 states responding to our query, nine (Alabama, Georgia, Florida, Louisiana, North Dakota, Nevada, South Carolina, Utah, and West Virginia) have a legislative mandate to administer some type of entrance assessment in kindergarten; a tenth (Oklahoma) mandates an assessment be administered during kindergarten. Specific mandates vary among the 10 states. Five states (Alabama, Georgia, South Carolina, Utah, and West Virginia) mandate the use of a specific standardized instrument (which varies among the five) and, with the exception of West Virginia, require that results be reported to the state office of education. The other states allow districts the flexibility to select the assessment instrument, and most do not require results to be reported. Some states consider entrance test results along with other data for placement decisions, but none advocate the use of results as the sole determinant for placement in kindergarten or promotion to 1st grade.

The purpose of this qualitative inquiry is to add to the literature a rich understanding of the experiences of teachers, parents, and administrators regarding two stated purposes of the standardized kindergarten entrance assessment: a) offering assistance for planning the curriculum, and b) providing information for parents to support literacy learning at home. The specific research question asked was: What are the perspectives of teachers, parents, and administrators concerning the use of standardized assessment for planning curriculum and literacy experiences at home?

Existing research (Burts et al., 1990; Fleege et al., 1993; Wodtke et al., 1989) is primarily quantitative, providing group data regarding the phenomenon of standardized testing of young children. This qualitative study enriches the literature by illuminating the multiple perspectives of the adult stakeholders (teachers, parents, and administrators) regarding the kindergarten assessment.

\section{Mandating Kindergarten}

Entrance Assessment in Utah

The mandated, statewide assessment in Utah was voted into law at the 1997 legislative session. Feeling that whatever teachers were doing "wasn't working," the bill's author proposed that a statewide assessment be developed and implemented in all kindergarten classrooms. The legislator's objective was to identify and address the 
ning and identify delays in children's literacy development is supported by early childhood teachers and researchers. Even though the state should be commended for its focus on young children and their families, standardized assessment is not the best tool to meet these objectives. By definition, standardized assessments are administered identically to each child and thus are hinged on inappropriate practice. Teachers are denied the flexibility to address the various developmental, individual, and cultural needs of children in their classrooms. Appropriate practice is further threatened by reporting the results to the state office of education, which heightens the potential for high-stakes testing.

Ongoing, performance-based assessment provides valid information that cannot be garnered from a single standardized assessment. Early childhood professionals advocate the need for assessing young children by using multiple measures over time and in the context of daily classroom activities. This enables teachers to adjust instruction from day to day to meet the changing needs of individual children in their classrooms.

The position on this issue is certainly not new. Theory and research (Burts, Hart, Charlesworth, \& Kirk, 1990; Fleege, Charlesworth, Burts, \& Hart, 1993; Kamii \& Kamii, 1990; Wodtke, Harper, Schommer, \& Brunelli, 1989) suggest that the use of standardized tests may harm young children. For years, early childhood scholars and researchers have advocated for performance-based assessment, rather than standardized measures, for instructional planning purposes. However, despite what we have learned about developmentally appropriate assessment, some inappropriate practices continue.

Of the 46 states responding to our query, nine (Alabama, Georgia, Florida, Louisiana, North Dakota, Nevada, South Carolina, Utah, and West Virginia) have a legislative mandate to administer some type of entrance assessment in kindergarten; a tenth (Oklahoma) mandates an assessment be administered during kindergarten. Specific mandates vary among the 10 states. Five states (Alabama, Georgia, South Carolina, Utah, and West Virginia) mandate the use of a specific standardized instrument (which varies among the five) and, with the exception of West Virginia, require that results be reported to the state office of education. The other states allow districts the flexibility to select the assessment instrument, and most do not require results to be reported. Some states consider entrance test results along with other data for placement decisions, but none advocate the use of results as the sole determinant for placement in kindergarten or promotion to 1st grade.

The purpose of this qualitative inquiry is to add to the literature a rich understanding of the experiences of teachers, parents, and administrators regarding two stated purposes of the standardized kindergarten entrance assessment: a) offering assistance for planning the curriculum, and b) providing information for parents to support literacy learning at home. The specific research question asked was: What are the perspectives of teachers, parents, and administrators concerning the use of standardized assessment for planning curriculum and literacy experiences at home?

Existing research (Burts et al., 1990; Fleege et al., 1993; Wodtke et al., 1989) is primarily quantitative, providing group data regarding the phenomenon of standardized testing of young children. This qualitative study enriches the literature by illuminating the multiple perspectives of the adult stakeholders (teachers, parents, and administrators) regarding the kindergarten assessment.

\section{Mandating Kindergarten}

Entrance Assessment in Utah

The mandated, statewide assessment in Utah was voted into law at the 1997 legislative session. Feeling that whatever teachers were doing "wasn't working," the bill's author proposed that a statewide assessment be developed and implemented in all kindergarten classrooms. The legislator's objective was to identify and address the 
ning and identify delays in children's literacy development is supported by early childhood teachers and researchers. Even though the state should be commended for its focus on young children and their families, standardized assessment is not the best tool to meet these objectives. By definition, standardized assessments are administered identically to each child and thus are hinged on inappropriate practice. Teachers are denied the flexibility to address the various developmental, individual, and cultural needs of children in their classrooms. Appropriate practice is further threatened by reporting the results to the state office of education, which heightens the potential for high-stakes testing.

Ongoing, performance-based assessment provides valid information that cannot be garnered from a single standardized assessment. Early childhood professionals advocate the need for assessing young children by using multiple measures over time and in the context of daily classroom activities. This enables teachers to adjust instruction from day to day to meet the changing needs of individual children in their classrooms.

The position on this issue is certainly not new. Theory and research (Burts, Hart, Charlesworth, \& Kirk, 1990; Fleege, Charlesworth, Burts, \& Hart, 1993; Kamii \& Kamii, 1990; Wodtke, Harper, Schommer, \& Brunelli, 1989) suggest that the use of standardized tests may harm young children. For years, early childhood scholars and researchers have advocated for performance-based assessment, rather than standardized measures, for instructional planning purposes. However, despite what we have learned about developmentally appropriate assessment, some inappropriate practices continue.

Of the 46 states responding to our query, nine (Alabama, Georgia, Florida, Louisiana, North Dakota, Nevada, South Carolina, Utah, and West Virginia) have a legislative mandate to administer some type of entrance assessment in kindergarten; a tenth (Oklahoma) mandates an assessment be administered during kindergarten. Specific mandates vary among the 10 states. Five states (Alabama, Georgia, South Carolina, Utah, and West Virginia) mandate the use of a specific standardized instrument (which varies among the five) and, with the exception of West Virginia, require that results be reported to the state office of education. The other states allow districts the flexibility to select the assessment instrument, and most do not require results to be reported. Some states consider entrance test results along with other data for placement decisions, but none advocate the use of results as the sole determinant for placement in kindergarten or promotion to 1st grade.

The purpose of this qualitative inquiry is to add to the literature a rich understanding of the experiences of teachers, parents, and administrators regarding two stated purposes of the standardized kindergarten entrance assessment: a) offering assistance for planning the curriculum, and $b$ ) providing information for parents to support literacy learning at home. The specific research question asked was: What are the perspectives of teachers, parents, and administrators concerning the use of standardized assessment for planning curriculum and literacy experiences at home?

Existing research (Burts et al., 1990; Fleege et al., 1993; Wodtke et al., 1989) is primarily quantitative, providing group data regarding the phenomenon of standardized testing of young children. This qualitative study enriches the literature by illuminating the multiple perspectives of the adult stakeholders (teachers, parents, and administrators) regarding the kindergarten assessment.

\section{Mandating Kindergarten}

Entrance Assessment in Utah

The mandated, statewide assessment in Utah was voted into law at the 1997 legislative session. Feeling that whatever teachers were doing "wasn't working," the bill's author proposed that a statewide assessment be developed and implemented in all kindergarten classrooms. The legislator's objective was to identify and address the 
ning and identify delays in children's literacy development is supported by early childhood teachers and researchers. Even though the state should be commended for its focus on young children and their families, standardized assessment is not the best tool to meet these objectives. By definition, standardized assessments are administered identically to each child and thus are hinged on inappropriate practice. Teachers are denied the flexibility to address the various developmental, individual, and cultural needs of children in their classrooms. Appropriate practice is further threatened by reporting the results to the state office of education, which heightens the potential for high-stakes testing.

Ongoing, performance-based assessment provides valid information that cannot be garnered from a single standardized assessment. Early childhood professionals advocate the need for assessing young children by using multiple measures over time and in the context of daily classroom activities. This enables teachers to adjust instruction from day to day to meet the changing needs of individual children in their classrooms.

The position on this issue is certainly not new. Theory and research (Burts, Hart, Charlesworth, \& Kirk, 1990; Fleege, Charlesworth, Burts, \& Hart, 1993; Kamii \& Kamii, 1990; Wodtke, Harper, Schommer, $\&$ Brunelli, 1989) suggest that the use of standardized tests may harm young children. For years, early childhood scholars and researchers have advocated for performance-based assessment, rather than standardized measures, for instructional planning purposes. However, despite what we have learned about developmentally appropriate assessment, some inappropriate practices continue.

Of the 46 states responding to our query, nine (Alabama, Georgia, Florida, Louisiana, North Dakota, Nevada, South Carolina, Utah, and West Virginia) have a legislative mandate to administer some type of entrance assessment in kindergarten; a tenth (Oklahoma) mandates an assessment be administered during kindergarten. Specific mandates vary among the 10 states. Five states (Alabama, Georgia, South Carolina, Utah, and West Virginia) mandate the use of a specific standardized instrument (which varies among the five) and, with the exception of West Virginia, require that results be reported to the state office of education. The other states allow districts the flexibility to select the assessment instrument, and most do not require results to be reported. Some states consider entrance test results along with other data for placement decisions, but none advocate the use of results as the sole determinant for placement in kindergarten or promotion to 1st grade.

The purpose of this qualitative inquiry is to add to the literature a rich understanding of the experiences of teachers, parents, and administrators regarding two stated purposes of the standardized kindergarten entrance assessment: a) offering assistance for planning the curriculum, and b) providing information for parents to support literacy learning at home. The specific research question asked was: What are the perspectives of teachers, parents, and administrators concerning the use of standardized assessment for planning curriculum and literacy experiences at home?

Existing research (Burts et al., 1990; Fleege et al., 1993; Wodtke et al., 1989) is primarily quantitative, providing group data regarding the phenomenon of standardized testing of young children. This qualitative study enriches the literature by illuminating the multiple perspectives of the adult stakeholders (teachers, parents, and administrators) regarding the kindergarten assessment.

\section{Mandating Kindergarten}

Entrance Assessment in Utah

The mandated, statewide assessment in Utah was voted into law at the 1997 legislative session. Feeling that whatever teachers were doing "wasn't working," the bill's author proposed that a statewide assessment be developed and implemented in all kindergarten classrooms. The legislator's objective was to identify and address the 
ning and identify delays in children's literacy development is supported by early childhood teachers and researchers. Even though the state should be commended for its focus on young children and their families, standardized assessment is not the best tool to meet these objectives. By definition, standardized assessments are administered identically to each child and thus are hinged on inappropriate practice. Teachers are denied the flexibility to address the various developmental, individual, and cultural needs of children in their classrooms. Appropriate practice is further threatened by reporting the results to the state office of education, which heightens the potential for high-stakes testing.

Ongoing, performance-based assessment provides valid information that cannot be garnered from a single standardized assessment. Early childhood professionals advocate the need for assessing young children by using multiple measures over time and in the context of daily classroom activities. This enables teachers to adjust instruction from day to day to meet the changing needs of individual children in their classrooms.

The position on this issue is certainly not new. Theory and research (Burts, Hart, Charlesworth, \& Kirk, 1990; Fleege, Charlesworth, Burts, \& Hart, 1993; Kamii \& Kamii, 1990; Wodtke, Harper, Schommer, \& Brunelli, 1989) suggest that the use of standardized tests may harm young children. For years, early childhood scholars and researchers have advocated for performance-based assessment, rather than standardized measures, for instructional planning purposes. However, despite what we have learned about developmentally appropriate assessment, some inappropriate practices continue.

Of the 46 states responding to our query, nine (Alabama, Georgia, Florida, Louisiana, North Dakota, Nevada, South Carolina, Utah, and West Virginia) have a legislative mandate to administer some type of entrance assessment in kindergarten; a tenth (Oklahoma) mandates an assessment be administered during kindergarten. Specific mandates vary among the 10 states. Five states (Alabama, Georgia, South Carolina, Utah, and West Virginia) mandate the use of a specific standardized instrument (which varies among the five) and, with the exception of West Virginia, require that results be reported to the state office of education. The other states allow districts the flexibility to select the assessment instrument, and most do not require results to be reported. Some states consider entrance test results along with other data for placement decisions, but none advocate the use of results as the sole determinant for placement in kindergarten or promotion to 1 st grade.

The purpose of this qualitative inquiry is to add to the literature a rich understanding of the experiences of teachers, parents, and administrators regarding two stated purposes of the standardized kindergarten entrance assessment: a) offering assistance for planning the curriculum, and $b$ ) providing information for parents to support literacy learning at home. The specific research question asked was: What are the perspectives of teachers, parents, and administrators concerning the use of standardized assessment for planning curriculum and literacy experiences at home?

Existing research (Burts et al., 1990; Fleege et al., 1993; Wodtke et al., 1989) is primarily quantitative, providing group data regarding the phenomenon of standardized testing of young children. This qualitative study enriches the literature by illuminating the multiple perspectives of the adult stakeholders (teachers, parents, and administrators) regarding the kindergarten assessment.

\section{Mandating Kindergarten}

\section{Entrance Assessment in Utah}

The mandated, statewide assessment in Utah was voted into law at the 1997 legislative session. Feeling that whatever teachers were doing "wasn't working," the bill's author proposed that a statewide assessment be developed and implemented in all kindergarten classrooms. The legislator's objective was to identify and address the 
ning and identify delays in children's literacy development is supported by early childhood teachers and researchers. Even though the state should be commended for its focus on young children and their families, standardized assessment is not the best tool to meet these objectives. By definition, standardized assessments are administered identically to each child and thus are hinged on inappropriate practice. Teachers are denied the flexibility to address the various developmental, individual, and cultural needs of children in their classrooms. Appropriate practice is further threatened by reporting the results to the state office of education, which heightens the potential for high-stakes testing.

Ongoing, performance-based assessment provides valid information that cannot be garnered from a single standardized assessment. Early childhood professionals advocate the need for assessing young children by using multiple measures over time and in the context of daily classroom activities. This enables teachers to adjust instruction from day to day to meet the changing needs of individual children in their classrooms.

The position on this issue is certainly not new. Theory and research (Burts, Hart, Charlesworth, \& Kirk, 1990; Fleege, Charlesworth, Burts, \& Hart, 1993; Kamii \& Kamii, 1990; Wodtke, Harper, Schommer, \& Brunelli, 1989) suggest that the use of standardized tests may harm young children. For years, early childhood scholars and researchers have advocated for performance-based assessment, rather than standardized measures, for instructional planning purposes. However, despite what we have learned about developmentally appropriate assessment, some inappropriate practices continue.

Of the 46 states responding to our query, nine (Alabama, Georgia, Florida, Louisiana, North Dakota, Nevada, South Carolina, Utah, and West Virginia) have a legislative mandate to administer some type of entrance assessment in kindergarten; a tenth (Oklahoma) mandates an assessment be administered during

kindergarten. Specific mandates vary among the 10 states. Five states (Alabama, Georgia, South Carolina, Utah, and West Virginia) mandate the use of a specific standardized instrument (which varies among the five) and, with the exception of West Virginia, require that results be reported to the state office of education. The other states allow districts the flexibility to select the assessment instrument, and most do not require results to be reported. Some states consider entrance test results along with other data for placement decisions, but none advocate the use of results as the sole determinant for placement in kindergarten or promotion to 1st grade.

The purpose of this qualitative inquiry is to add to the literature a rich understanding of the experiences of teachers, parents, and administrators regarding two stated purposes of the standardized kindergarten entrance assessment: a) offering assistance for planning the curriculum, and b) providing information for parents to support literacy learning at home. The specific research question asked was: What are the perspectives of teachers, parents, and administrators concerning the use of standardized assessment for planning curriculum and literacy experiences at home?

Existing research (Burts et al., 1990; Fleege et al., 1993; Wodtke et al., 1989) is primarily quantitative, providing group data regarding the phenomenon of standardized testing of young children. This qualitative study enriches the literature by illuminating the multiple perspectives of the adult stakeholders (teachers, parents, and administrators) regarding the kindergarten assessment.

\section{Mandating Kindergarten}

Entrance Assessment in Utah

The mandated, statewide assessment in Utah was voted into law at the 1997 legislative session. Feeling that whatever teachers were doing "wasn't working," the bill's author proposed that a statewide assessment be developed and implemented in all kindergarten classrooms. The legislator's objective was to identify and address the 
ning and identify delays in children's literacy development is supported by early childhood teachers and researchers. Even though the state should be commended for its focus on young children and their families, standardized assessment is not the best tool to meet these objectives. By definition, standardized assessments are administered identically to each child and thus are hinged on inappropriate practice. Teachers are denied the flexibility to address the various developmental, individual, and cultural needs of children in their classrooms. Appropriate practice is further threatened by reporting the results to the state office of education, which heightens the potential for high-stakes testing.

Ongoing, performance-based assessment provides valid information that cannot be garnered from a single standardized assessment. Early childhood professionals advocate the need for assessing young children by using multiple measures over time and in the context of daily classroom activities. This enables teachers to adjust instruction from day to day to meet the changing needs of individual children in their classrooms.

The position on this issue is certainly not new. Theory and research (Burts, Hart, Charlesworth, \& Kirk, 1990; Fleege, Charlesworth, Burts, \& Hart, 1993; Kamii \& Kamii, 1990; Wodtke, Harper, Schommer, \& Brunelli, 1989) suggest that the use of standardized tests may harm young children. For years, early childhood scholars and researchers have advocated for performance-based assessment, rather than standardized measures, for instructional planning purposes. However, despite what we have learned about developmentally appropriate assessment, some inappropriate practices continue.

Of the 46 states responding to our query, nine (Alabama, Georgia, Florida, Louisiana, North Dakota, Nevada, South Carolina, Utah, and West Virginia) have a legislative mandate to administer some type of entrance assessment in kindergarten; a tenth (Oklahoma) mandates an assessment be administered during

kindergarten. Specific mandates vary among the 10 states. Five states (Alabama, Georgia, South Carolina, Utah, and West Virginia) mandate the use of a specific standardized instrument (which varies among the five) and, with the exception of West Virginia, require that results be reported to the state office of education. The other states allow districts the flexibility to select the assessment instrument, and most do not require results to be reported. Some states consider entrance test results along with other data for placement decisions, but none advocate the use of results as the sole determinant for placement in kindergarten or promotion to 1st grade.

The purpose of this qualitative inquiry is to add to the literature a rich understanding of the experiences of teachers, parents, and administrators regarding two stated purposes of the standardized kindergarten entrance assessment: a) offering assistance for planning the curriculum, and b) providing information for parents to support literacy learning at home. The specific research question asked was: What are the perspectives of teachers, parents, and administrators concerning the use of standardized assessment for planning curriculum and literacy experiences at home?

Existing research (Burts et al., 1990; Fleege et al., 1993; Wodtke et al., 1989) is primarily quantitative, providing group data regarding the phenomenon of standardized testing of young children. This qualitative study enriches the literature by illuminating the multiple perspectives of the adult stakeholders (teachers, parents, and administrators) regarding the kindergarten assessment.

\section{Mandating Kindergarten}

Entrance Assessment in Utah

The mandated, statewide assessment in Utah was voted into law at the 1997 legislative session. Feeling that whatever teachers were doing "wasn't working," the bill's author proposed that a statewide assessment be developed and implemented in all kindergarten classrooms. The legislator's objective was to identify and address the 
ning and identify delays in children's literacy development is supported by early childhood teachers and researchers. Even though the state should be commended for its focus on young children and their families, standardized assessment is not the best tool to meet these objectives. By definition, standardized assessments are administered identically to each child and thus are hinged on inappropriate practice. Teachers are denied the flexibility to address the various developmental, individual, and cultural needs of children in their classrooms. Appropriate practice is further threatened by reporting the results to the state office of education, which heightens the potential for high-stakes testing.

Ongoing, performance-based assessment provides valid information that cannot be garnered from a single standardized assessment. Early childhood professionals advocate the need for assessing young children by using multiple measures over time and in the context of daily classroom activities. This enables teachers to adjust instruction from day to day to meet the changing needs of individual children in their classrooms.

The position on this issue is certainly not new. Theory and research (Burts, Hart, Charlesworth, \& Kirk, 1990; Fleege, Charlesworth, Burts, \& Hart, 1993; Kamii \& Kamii, 1990; Wodtke, Harper, Schommer, \& Brunelli, 1989) suggest that the use of standardized tests may harm young children. For years, early childhood scholars and researchers have advocated for performance-based assessment, rather than standardized measures, for instructional planning purposes. However, despite what we have learned about developmentally appropriate assessment, some inappropriate practices continue.

Of the 46 states responding to our query, nine (Alabama, Georgia, Florida, Louisiana, North Dakota, Nevada, South Carolina, Utah, and West Virginia) have a legislative mandate to administer some type of entrance assessment in kindergarten; a tenth (Oklahoma) mandates an assessment be administered during kindergarten. Specific mandates vary among the 10 states. Five states (Alabama, Georgia, South Carolina, Utah, and West Virginia) mandate the use of a specific standardized instrument (which varies among the five) and, with the exception of West Virginia, require that results be reported to the state office of education. The other states allow districts the flexibility to select the assessment instrument, and most do not require results to be reported. Some states consider entrance test results along with other data for placement decisions, but none advocate the use of results as the sole determinant for placement in kindergarten or promotion to 1st grade.

The purpose of this qualitative inquiry is to add to the literature a rich understanding of the experiences of teachers, parents, and administrators regarding two stated purposes of the standardized kindergarten entrance assessment: a) offering assistance for planning the curriculum, and $b$ ) providing information for parents to support literacy learning at home. The specific research question asked was: What are the perspectives of teachers, parents, and administrators concerning the use of standardized assessment for planning curriculum and literacy experiences at home?

Existing research (Burts et al., 1990; Fleege et al., 1993; Wodtke et al., 1989) is primarily quantitative, providing group data regarding the phenomenon of standardized testing of young children. This qualitative study enriches the literature by illuminating the multiple perspectives of the adult stakeholders (teachers, parents, and administrators) regarding the kindergarten assessment.

\section{Mandating Kindergarten \\ Entrance Assessment in Utah}

The mandated, statewide assessment in Utah was voted into law at the 1997 legislative session. Feeling that whatever teachers were doing "wasn't working," the bill's author proposed that a statewide assessment be developed and implemented in all kindergarten classrooms. The legislator's objective was to identify and address the 
ning and identify delays in children's literacy development is supported by early childhood teachers and researchers. Even though the state should be commended for its focus on young children and their families, standardized assessment is not the best tool to meet these objectives. By definition, standardized assessments are administered identically to each child and thus are hinged on inappropriate practice. Teachers are denied the flexibility to address the various developmental, individual, and cultural needs of children in their classrooms. Appropriate practice is further threatened by reporting the results to the state office of education, which heightens the potential for high-stakes testing.

Ongoing, performance-based assessment provides valid information that cannot be garnered from a single standardized assessment. Early childhood professionals advocate the need for assessing young children by using multiple measures over time and in the context of daily classroom activities. This enables teachers to adjust instruction from day to day to meet the changing needs of individual children in their classrooms.

The position on this issue is certainly not new. Theory and research (Burts, Hart, Charlesworth, \& Kirk, 1990; Fleege, Charlesworth, Burts, \& Hart, 1993; Kamii \& Kamii, 1990; Wodtke, Harper, Schommer, \& Brunelli, 1989) suggest that the use of standardized tests may harm young children. For years, early childhood scholars and researchers have advocated for performance-based assessment, rather than standardized measures, for instructional planning purposes. However, despite what we have learned about developmentally appropriate assessment, some inappropriate practices continue.

Of the 46 states responding to our query, nine (Alabama, Georgia, Florida, Louisiana, North Dakota, Nevada, South Carolina, Utah, and West Virginia) have a legislative mandate to administer some type of entrance assessment in kindergarten; a tenth (Oklahoma) mandates an assessment be administered during kindergarten. Specific mandates vary among the 10 states. Five states (Alabama, Georgia, South Carolina, Utah, and West Virginia) mandate the use of a specific standardized instrument (which varies among the five) and, with the exception of West Virginia, require that results be reported to the state office of education. The other states allow districts the flexibility to select the assessment instrument, and most do not require results to be reported. Some states consider entrance test results along with other data for placement decisions, but none advocate the use of results as the sole determinant for placement in kindergarten or promotion to 1st grade.

The purpose of this qualitative inquiry is to add to the literature a rich understanding of the experiences of teachers, parents, and administrators regarding two stated purposes of the standardized kindergarten entrance assessment: a) offering assistance for planning the curriculum, and $b$ ) providing information for parents to support literacy learning at home. The specific research question asked was: What are the perspectives of teachers, parents, and administrators concerning the use of standardized assessment for planning curriculum and literacy experiences at home?

Existing research (Burts et al., 1990; Fleege et al., 1993; Wodtke et al., 1989) is primarily quantitative, providing group data regarding the phenomenon of standardized testing of young children. This qualitative study enriches the literature by illuminating the multiple perspectives of the adult stakeholders (teachers, parents, and administrators) regarding the kindergarten assessment.

\section{Mandating Kindergarten \\ Entrance Assessment in Utah}

The mandated, statewide assessment in Utah was voted into law at the 1997 legislative session. Feeling that whatever teachers were doing "wasn't working," the bill's author proposed that a statewide assessment be developed and implemented in all kindergarten classrooms. The legislator's objective was to identify and address the 
ning and identify delays in children's literacy development is supported by early childhood teachers and researchers. Even though the state should be commended for its focus on young children and their families, standardized assessment is not the best tool to meet these objectives. By definition, standardized assessments are administered identically to each child and thus are hinged on inappropriate practice. Teachers are denied the flexibility to address the various developmental, individual, and cultural needs of children in their classrooms. Appropriate practice is further threatened by reporting the results to the state office of education, which heightens the potential for high-stakes testing.

Ongoing, performance-based assessment provides valid information that cannot be garnered from a single standardized assessment. Early childhood professionals advocate the need for assessing young children by using multiple measures over time and in the context of daily classroom activities. This enables teachers to adjust instruction from day to day to meet the changing needs of individual children in their classrooms.

The position on this issue is certainly not new. Theory and research (Burts, Hart, Charlesworth, \& Kirk, 1990; Fleege, Charlesworth, Burts, \& Hart, 1993; Kamii \& Kamii, 1990; Wodtke, Harper, Schommer, \& Brunelli, 1989) suggest that the use of standardized tests may harm young children. For years, early childhood scholars and researchers have advocated for performance-based assessment, rather than standardized measures, for instructional planning purposes. However, despite what we have learned about developmentally appropriate assessment, some inappropriate practices continue.

Of the 46 states responding to our query, nine (Alabama, Georgia, Florida, Louisiana, North Dakota, Nevada, South Carolina, Utah, and West Virginia) have a legislative mandate to administer some type of entrance assessment in kindergarten; a tenth (Oklahoma) mandates an assessment be administered during kindergarten. Specific mandates vary among the 10 states. Five states (Alabama, Georgia, South Carolina, Utah, and West Virginia) mandate the use of a specific standardized instrument (which varies among the five) and, with the exception of West Virginia, require that results be reported to the state office of education. The other states allow districts the flexibility to select the assessment instrument, and most do not require results to be reported. Some states consider entrance test results along with other data for placement decisions, but none advocate the use of results as the sole determinant for placement in kindergarten or promotion to 1st grade.

The purpose of this qualitative inquiry is to add to the literature a rich understanding of the experiences of teachers, parents, and administrators regarding two stated purposes of the standardized kindergarten entrance assessment: a) offering assistance for planning the curriculum, and $b$ ) providing information for parents to support literacy learning at home. The specific research question asked was: What are the perspectives of teachers, parents, and administrators concerning the use of standardized assessment for planning curriculum and literacy experiences at home?

Existing research (Burts et al., 1990; Fleege et al., 1993; Wodtke et al., 1989) is primarily quantitative, providing group data regarding the phenomenon of standardized testing of young children. This qualitative study enriches the literature by illuminating the multiple perspectives of the adult stakeholders (teachers, parents, and administrators) regarding the kindergarten assessment.

\section{Mandating Kindergarten}

Entrance Assessment in Utah

The mandated, statewide assessment in Utah was voted into law at the 1997 legislative session. Feeling that whatever teachers were doing "wasn't working," the bill's author proposed that a statewide assessment be developed and implemented in all kindergarten classrooms. The legislator's objective was to identify and address the 
ning and identify delays in children's literacy development is supported by early childhood teachers and researchers. Even though the state should be commended for its focus on young children and their families, standardized assessment is not the best tool to meet these objectives. By definition, standardized assessments are administered identically to each child and thus are hinged on inappropriate practice. Teachers are denied the flexibility to address the various developmental, individual, and cultural needs of children in their classrooms. Appropriate practice is further threatened by reporting the results to the state office of education, which heightens the potential for high-stakes testing.

Ongoing, performance-based assessment provides valid information that cannot be garnered from a single standardized assessment. Early childhood professionals advocate the need for assessing young children by using multiple measures over time and in the context of daily classroom activities. This enables teachers to adjust instruction from day to day to meet the changing needs of individual children in their classrooms.

The position on this issue is certainly not new. Theory and research (Burts, Hart, Charlesworth, \& Kirk, 1990; Fleege, Charlesworth, Burts, \& Hart, 1993; Kamii \& Kamii, 1990; Wodtke, Harper, Schommer, \& Brunelli, 1989) suggest that the use of standardized tests may harm young children. For years, early childhood scholars and researchers have advocated for performance-based assessment, rather than standardized measures, for instructional planning purposes. However, despite what we have learned about developmentally appropriate assessment, some inappropriate practices continue.

Of the 46 states responding to our query, nine (Alabama, Georgia, Florida, Louisiana, North Dakota, Nevada, South Carolina, Utah, and West Virginia) have a legislative mandate to administer some type of entrance assessment in kindergarten; a tenth (Oklahoma) mandates an assessment be administered during

kindergarten. Specific mandates vary among the 10 states. Five states (Alabama, Georgia, South Carolina, Utah, and West Virginia) mandate the use of a specific standardized instrument (which varies among the five) and, with the exception of West Virginia, require that results be reported to the state office of education. The other states allow districts the flexibility to select the assessment instrument, and most do not require results to be reported. Some states consider entrance test results along with other data for placement decisions, but none advocate the use of results as the sole determinant for placement in kindergarten or promotion to 1st grade.

The purpose of this qualitative inquiry is to add to the literature a rich understanding of the experiences of teachers, parents, and administrators regarding two stated purposes of the standardized kindergarten entrance assessment: a) offering assistance for planning the curriculum, and b) providing information for parents to support literacy learning at home. The specific research question asked was: What are the perspectives of teachers, parents, and administrators concerning the use of standardized assessment for planning curriculum and literacy experiences at home?

Existing research (Burts et al., 1990; Fleege et al., 1993; Wodtke et al., 1989) is primarily quantitative, providing group data regarding the phenomenon of standardized testing of young children. This qualitative study enriches the literature by illuminating the multiple perspectives of the adult stakeholders (teachers, parents, and administrators) regarding the kindergarten assessment.

\section{Mandating Kindergarten}

Entrance Assessment in Utah

The mandated, statewide assessment in Utah was voted into law at the 1997 legislative session. Feeling that whatever teachers were doing "wasn't working," the bill's author proposed that a statewide assessment be developed and implemented in all kindergarten classrooms. The legislator's objective was to identify and address the 
ning and identify delays in children's literacy development is supported by early childhood teachers and researchers. Even though the state should be commended for its focus on young children and their families, standardized assessment is not the best tool to meet these objectives. By definition, standardized assessments are administered identically to each child and thus are hinged on inappropriate practice. Teachers are denied the flexibility to address the various developmental, individual, and cultural needs of children in their classrooms. Appropriate practice is further threatened by reporting the results to the state office of education, which heightens the potential for high-stakes testing.

Ongoing, performance-based assessment provides valid information that cannot be garnered from a single standardized assessment. Early childhood professionals advocate the need for assessing young children by using multiple measures over time and in the context of daily classroom activities. This enables teachers to adjust instruction from day to day to meet the changing needs of individual children in their classrooms.

The position on this issue is certainly not new. Theory and research (Burts, Hart, Charlesworth, \& Kirk, 1990; Fleege, Charlesworth, Burts, \& Hart, 1993; Kamii \& Kamii, 1990; Wodtke, Harper, Schommer, $\&$ Brunelli, 1989) suggest that the use of standardized tests may harm young children. For years, early childhood scholars and researchers have advocated for performance-based assessment, rather than standardized measures, for instructional planning purposes. However, despite what we have learned about developmentally appropriate assessment, some inappropriate practices continue.

Of the 46 states responding to our query, nine (Alabama, Georgia, Florida, Louisiana, North Dakota, Nevada, South Carolina, Utah, and West Virginia) have a legislative mandate to administer some type of entrance assessment in kindergarten; a tenth (Oklahoma) mandates an assessment be administered during kindergarten. Specific mandates vary among the 10 states. Five states (Alabama, Georgia, South Carolina, Utah, and West Virginia) mandate the use of a specific standardized instrument (which varies among the five) and, with the exception of West Virginia, require that results be reported to the state office of education. The other states allow districts the flexibility to select the assessment instrument, and most do not require results to be reported. Some states consider entrance test results along with other data for placement decisions, but none advocate the use of results as the sole determinant for placement in kindergarten or promotion to 1st grade.

The purpose of this qualitative inquiry is to add to the literature a rich understanding of the experiences of teachers, parents, and administrators regarding two stated purposes of the standardized kindergarten entrance assessment: a) offering assistance for planning the curriculum, and b) providing information for parents to support literacy learning at home. The specific research question asked was: What are the perspectives of teachers, parents, and administrators concerning the use of standardized assessment for planning curriculum and literacy experiences at home?

Existing research (Burts et al., 1990; Fleege et al., 1993; Wodtke et al., 1989) is primarily quantitative, providing group data regarding the phenomenon of standardized testing of young children. This qualitative study enriches the literature by illuminating the multiple perspectives of the adult stakeholders (teachers, parents, and administrators) regarding the kindergarten assessment.

\section{Mandating Kindergarten}

Entrance Assessment in Utah

The mandated, statewide assessment in Utah was voted into law at the 1997 legislative session. Feeling that whatever teachers were doing "wasn't working," the bill's author proposed that a statewide assessment be developed and implemented in all kindergarten classrooms. The legislator's objective was to identify and address the 
needs of students whose literacy learning lags behind their counterparts. In the words of the author of the bill,

I've listened to a lot of problems ... kids who are delinquents. We're finding that nearly all of them ... couldn't read. . . My thought was, okay, let's see what they're like coming in and let's identify those that are behind the pack and see if there's something we can do to help them move up into the pack. (B. Haymond, personal communication, September 28, 1998)

The statewidekindergarten assessment was piloted during the 1997-98 academic year, revised based on feedback from school districts, and continues as a requirement for all children entering kindergarten in Utah. Parents bring their children to school at an appointed time during the first two weeks of the school year, when the assessment is administered individually by the teacher. A teacher manual indicates how to administer the test, and even provides a script for administering it. During the assessment, the children are asked to verbally respond to questions; the teacher marks each response on a Scantron sheet. Testing each child takes approximately 45 minutes.

The assessment instrument was designed to measure the content of Utah's kindergarten core curriculum generally, in the areas of literacy and numeric skills. Validity and reliability data are not available. The test is purported to objectively measure children's understanding of: a) concepts of print, b) visual discrimination/ phonemic awareness, c) comprehension, d) speaking/listening, e) number, and f) social adaptation. The tasks on the test include: a) identification of words and letters, b) matching pictures of words that rhyme or begin with the same sound, c) counting to 20 , d) writing their names, and e) answering comprehension questions after hearing a story. Each test item has one right answer. For example, children are asked to point to the place on the page where one starts reading, and to name letters as the teacher points to them. In some cases, parents were present during the assessment; in other cases, they were asked to wait outside the room.

\section{Theoretical Framework}

Early childhood education literature provides research-based guidelines for instruction and assessment in kindergarten and the primary grades. The National Association for the Education of Young Children (NAEYC) asserts that young children demonstrate tremendous individual variation in timing and patterns of their social, emotional, physical, and cognitive growth. Young children primarily understand their world from a point of view based on their unique prior experiences; they do not yet have the capacity to think abstractly in the way that older children do. Young children tend to overrate their competence due in part to egocentrism, and in part to their rapidly changing development. Although young children often view themselves as highly competent, they can easily become discouraged as a result of frequent disapproval and failure (Bredekamp \& Copple, 1997). Thus, best practice in the primary grades involves social interaction, manipulation of objects, opportunities to work in flexible small groups, and being able to choose from a variety of activities.

Assessment designed to inform developmentally appropriate practice for young children should be ongoing and aligned with viable, appropriate goals for their education. The NAEYC position is:

Teachers use observational assessment of children's progress, examination of children's work samples, and documentation of their development and learning to plan and adapt curriculum to meet individual children's developmental or learning needs, identify children who may have a learning or developmental problem, communicate with parents, and evaluate the program's effectiveness. ... Decisions that have a major impact on children are based on multiple sources of information, including that obtained from observations by teachers and parents and specialists. (Bredekamp \& Copple, 1997, p. 133) 
Assessment should be embedded in instruction over time (Vukelich, 1997). Observation of children as they complete a task is a more natural form of assessment, is less stressful to children, and provides a better understanding of children's performance than standardized assessments (Culbertson \& Jalongo, 1999). For example, Meisels' (1993) Work Sampling System includes checklists to track children's mastery of important behaviors; portfolios, which serve as rich documentation of what they have done; and summary reports. In their study of 100 kindergartners, Meisels, Liaw, Dorfman, and Nelson (1995) verified the reliability and criterion validity of the Work Sampling System as a measure of the children's overall achievement.

Murphy and Baker (1990) suggest the following guidelines for assessing to inform instruction: a) teachers themselves must complete the assessment for it to be useful, b) assessment must be rooted in classroom activities as much as possible, and c) assessment must take into account the process of development over time, rather than compare each child to other children on a given day (pp. 107-108).

Standardized testing, intended to improve education by focusing attention and money on the needs of teachers and students, in reality has been costly in terms of dollars and instructional time (Puckett \& Black, 1994). In addition, most testing in the early grades not only disrupts teaching, but also is frustrating for teachers and children alike (Anderson, 1998; Haladyna, Haas, \& Allison, 1998). Research (Fleege et al., 1993; Wodtke et al., 1989) confirms that many young children experience stress during formal testing, demonstrating behaviors such as fidgeting, playing with their hair, and crying.

Kamii and Kamii (1990) call for a halt to achievement testing in grades K-2, because the pressure for higher test scores often results in classroom practices that are harmful to young children's development. These harmful classroom practices include: a) academic "redshirting,"b) retention, and c) pressure on teachers to provide academic instruction in developmentally inappropriate ways.

First, research provides evidence that retention, extra-year approaches, and academic redshirting are harmful to children. Shepard and Smith (1986) found that retention does not increase achievement. Similarly, Puckett and Black (1994) assert that extra-year approaches: a) bring about little, if any, academic benefit; b) cause some harm to children's social-emotional development; and c) are correlated to higher drop-out rates.

Finally, early childhood education scholars suggest that a narrow academic curriculum in kindergarten has a negative effect on children's development (Burts et al., 1990; Puckett \& Black, 1994; Wodtke et al., 1989). For example, significantly more stress behaviors were observed in children enrolled in developmentally inappropriate kindergartens than in their counterparts enrolled in developmentally appropriate kindergartens (Burts et al., 1990). Furthermore, Shepard and Smith (1988) suggest that highly academic kindergarten programs stifle natural exploration, detach reading from normal language development, and substitute inappropriate symbolic learning for more appropriate manipulative learning.

\section{Method}

A qualitative design was selected for this inquiry, to garner an in-depth understanding of the experiences of teachers, administrators, and parents regarding how the assessment assists them with instructional planning and literacy learning at home. The phenomenon of interest was the strengths and weaknesses of the assessment, as perceived by these stakeholders.

\section{Research Design}

The researchers used purposeful sampling (Lincoln \& Guba, 1985) to identify demographically diverse groups of informants for our study. We sought demographic diversity because characteristics such as gender, ethnicity, SES, and level of education influence individual perspectives. A 
demographically diverse group of informants would offer a better understanding of the human experience. Two criteria determined the selection of informants: 1) they (teachers, administrators, or parents) had to have been involved in the kindergarten assessment during the '97-'98 academic year; and 2) they had to enrich the demographic diversity of the informant pool based on relationship to the child (teacher, administrator, parent), gender, level of education, school type (rural, urban, suburban), and SES (Title I/not Title I). The informants were all of European descent, something that was virtually unavoidable, given that Utah's population is $95 \%$ white (U.S. Bureau of the Census, 1999). The informants represent five schools across four districts in Utah, including two Title I schools, two middle SES schools, and a professional development school. (Tables 1, 2 , and 3 provide demographic information, using pseudonyms to protect anonymity.)

To identify specific informants for inclusion in the study, the researchers used the "snowballing technique," whereby study participants identified other individuals (Bogdan \& Biklen, 1998). Thus, the first informants were known to the researchers, and they then suggested others for participation in the study.

Data were systematically collected via open-ended, focus group interviews, conducted from July to December 1998. A focus group format was appropriate because the study did not seek to reach a consensus or make decisions; rather, the aim was to acquire the richness of peer dialogue, as well as to find out as much as possible about the informants' experiences

Table 1

Parent Characteristics

\begin{tabular}{|c|c|c|c|c|c|}
\hline Name & $\begin{array}{l}\text { Ethnic } \\
\text { Origin }\end{array}$ & Gender & $\begin{array}{l}\text { Highest } \\
\text { Degree }\end{array}$ & $\begin{array}{c}\text { Child's School } \\
\text { Type }\end{array}$ & $\begin{array}{c}\text { Child's Age/Birth } \\
\text { Order }\end{array}$ \\
\hline Mick & Euro-American & M & Master's & City & 5.6/only \\
\hline Donna & Euro-American & $\mathrm{F}$ & Master's & City & $5.6 / 2 \mathrm{nd}$ of 2 \\
\hline Tami & Euro-American & $\mathrm{F}$ & High School & Urban/Title I & $5.3 / 1$ st of 2 \\
\hline Cari & Euro-American & $\mathrm{F}$ & Bachelor's & Urban/Title I & $5.11 / 2 \mathrm{nd}$ of 2 \\
\hline Anna & Euro-American & $\mathrm{F}$ & High School & City & $5.11 / 1$ st of 2 \\
\hline Sally & Euro-American & $\mathrm{F}$ & Master's & City & $5.6 /$ only \\
\hline
\end{tabular}

Table 2

Teacher Characteristics

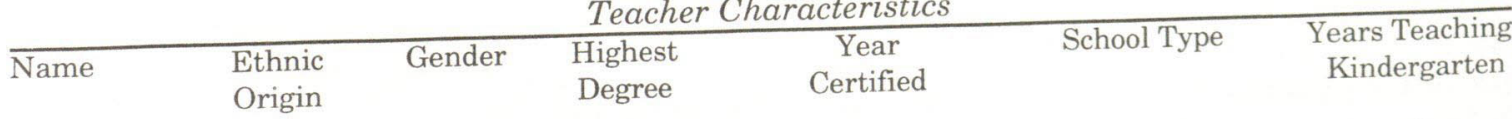

$\begin{array}{lllllcc} & & & & \text { Rural } & 4 \\ \text { Lois } & \text { Euro-American } & \text { F } & \text { Bachelor's } & 1978 & \text { City/Title 1 } & 12 \\ \text { Julia } & \text { Euro-American } & \text { F } & \text { Bachelor's } & 1974 & \text { Rural/Title I } & 18 \\ \text { Heidi } & \text { Euro-American } & \text { F } & \text { Bachelor's } & 1967 & \text { Urbanl/Title I } & 8 \\ \text { Betty } & \text { Euro-American } & \text { F } & \text { Bachelor's } & 1990 & \text { City } & 5 \\ \text { Pricilla } & \text { Euro-American } & \text { F } & \text { Bachelor's } & 1993 & \text { City } & 5 \\ \text { Robbie } & \text { Euro-American } & \text { F } & \text { Bachelor's } & 1984 & \end{array}$

Table 3

Administrator Characteristics

\begin{tabular}{|c|c|c|c|c|c|}
\hline Name & $\begin{array}{l}\text { Ethnic } \\
\text { Origin }\end{array}$ & Gender & $\begin{array}{l}\text { Early Childhood } \\
\text { Certified }\end{array}$ & $\begin{array}{l}\text { Present Position/ } \\
\text { Number of Years }\end{array}$ & $\begin{array}{c}\text { School/ } \\
\text { District Type }\end{array}$ \\
\hline $\begin{array}{l}\text { Bob } \\
\text { Hazel }\end{array}$ & Euro-American & M & $\mathrm{N}$ & Principal/11 & $\begin{array}{c}\text { City } \\
\text { Professional Dev. School }\end{array}$ \\
\hline $\begin{array}{l}\text { Hazel } \\
\text { Kevin }\end{array}$ & $\begin{array}{l}\text { Euro-American } \\
\text { Euro-American }\end{array}$ & $\begin{array}{l}\mathrm{F} \\
\mathrm{M}\end{array}$ & $\begin{array}{l}\mathrm{Y} \\
\mathrm{N}\end{array}$ & $\begin{array}{l}\text { Principal/3 } \\
\text { Principal/6 }\end{array}$ & $\begin{array}{l}\text { Professional Dev. Schoos } \\
\text { Rural }\end{array}$ \\
\hline Robert & Euro-American & M & $\mathrm{N}$ & $\begin{array}{l}\text { District Curriculum } \\
\text { Coordinator/15 }\end{array}$ & City \\
\hline
\end{tabular}


and feelings (Morgan \& Krueger, 1993). Teachers, parents, and administrators were interviewed in groups of three or four, such that all members of a focus group had the same role (i.e., all teachers, all parents, all administrators). This structure allowed rich information to be obtained through peer dialogue, while avoiding the problems inherent in placing superordinates and subordinates in the same focus group (Morgan \& Krueger, 1993). Membership in a particular focus group was based on the scheduling needs of the informants.

The researchers collaboratively developed open-ended interview questions and each conducted half of the interviews. The open-ended interview format provided the flexibility to probe informants' responses and illuminate individual perspectives. In general, all informants were asked what they saw as strengths and weaknesses of the assessment. In addition, teachers were asked what type of assessment they used prior to the state-mandated one, and how the new assessment assisted them with instructional planning. They were also asked whether they used any other assessment in conjunction with the statemandated one. Parents were asked whether they felt the assessment was helpful either to them or their child. Administrators were asked how they perceived the assessment to be helpful to teachers and parents, and how it aligned with developmentally appropriate practice.

Transcriptions of the focus group interviews served as the data source. Bi-monthly (from July '98-February '99) meetings were held to review data and work on data analysis. Data analysis was ongoing, and an audit trail (Lincoln \& Guba, 1985) was developed and maintained. The audit trail is identified in the findings to verify that the categories of data represent multiple perspectives. Two letters follow each direct quote: the first one notes whether the quote came from a parent $(\mathrm{P})$, teacher $(\mathrm{T})$, or administrator (A), and the second notes the first initial of the informant's pseudonym.

The constant comparative method of data analysis (Lincoln \& Guba, 1985) was

employed toidentify and code units of meaning that captured the essence of the informants' experiences. Data were gathered until no new themes emerged. When all data were coded, any necessary member checks were completed (Lincoln \& Guba, 1995) to verify the interpretations. During data analysis, nine peer examiners reviewed and commented on the analysis of the data. In general, the peer examiners agreed with the data analysis (coding made sense to them), although a few units of meaning (informants' statements) were recoded to better fit into the scheme. In addition, meetings with the peer examiners resulted in the recoding of data, when five general themes were condensed into the three reported here. Consensus was reached with the peer reviewers on the recoding scheme.

Various strategies were employed to ensure the trustworthiness of this inquiry. First, data were triangulated via multiple informants, so that the categories were confirmed across multiple perspectives. The researchers' bias was addressed by asking nine peer examiners to comment on their interpretation of the data. Furthermore, member checks verified interpretations with the informants, who also reviewed a late draft of the report. An audit trail allowed confirmation that researcher inferences were grounded in the perspectives of the informants.

\section{Findings}

Curriculum, time, and well-being of children, parents, and teachers emerged from the data as the major themes. Because the informants viewed particular aspects of the assessment practice as strengths or weaknesses, the report is organized by discussing each theme-curriculum, time, well-being of children, parents, and teachers-in terms of the strengths and weaknesses identified by the informants.

\section{Curriculum}

Strengths. Strengths of the assessment, as cited by teachers, administrators, and parents in the category of curriculum, included the immediacy of gaining some in- 
formation about children's skills, and having the opportunity to begin a dialogue between parents and teachers. An additional strength that emerged was consistency of information across schools in the state and with the core curriculum.

Among the teachers, Heidi was the most enthusiastic about the assessment. She felt that the experience provided her with a lot of information including what she learned by meeting the parents individually. "I loved it. Really, I did. I loved giving it. We know children in our class right away. I even loved having the parents in the room, because it told me a lot" (T-H).

The assessment provided a good beginning reference point for planning instruction. Kevin noted, "One positive feedback I've gotten from teachers that I agree with is, at least it gives them a reference point at the beginning of the year so they know some of the strengths and weaknesses of their students" (A-K). Julia created charts of children's strengths and weaknesses so that she could quickly note, "those children who don't write their name, those who don't recognize any letters. . . . It gave me a ballpark picture of which kids I needed to work with on visual discrimination" (T-J). Robbie added, "Some of the [kids'] questions were 'Where does the story begin?' 'Show me where the text is.' This tells me as a teacher that this child has been read to" (T-R).

Some parents valued the initial information derived from the assessment, noting it as an opportunity to find out where their children needed help to be successful in kindergarten. Tami commented,

I was able to sit in here while [my son] did his [assessment]. [The teacher] told a story, and she wanted to see how much he remembered from the story; it was just good for me to see all of the things that he was capable of doing and what I needed to help him with. (P-T)

Cari added, "You know where their weaknesses were and where you could help them at home because you seen [sic\} as they were tested. . . . I was glad to be able to see ... I need to work with that" (P-C).
The opportunity for teachers, parents, and children to meet and begin dialogue was viewed as a strength of the assessment. Bob felt this was valuable in terms of information that can be exchanged to support curriculum development. He commented,

I think the two most valuable things that are happening as a result of this is ... the opportunity to come in and [for] parents and teachers [to] begin that discussion about the child and open up that dialogue and the one-on-one with the teacher. (A-B)

Julia felt the instrument assisted her as she talked to parents about the results. She noted, "What is so nice about this data is to be able to say, "This is an area that your child is going to need reinforcement in and here is one they are really, really good at" (T-J). She later added, "When I graphed out [the results], it was helpful to me to be able to cover up names and say [to parents], "Do you see how all the kids are low in this area?"” (T-J).

Teachers also liked the statewide consistency of the test, because it provided immediate information on children entering mid-year. Said Heidi, "[The test is] very helpful when [children] come in the middle of the year. You can see what they did on the test and you know exactly what kind of test it is" (T-H). Julia also felt the results on children coming mid-year were quick and easy to read:

We have a $25 \%$ turnover rate at our school, so it is really helpful at our school. With that many students entering mid-year, it is really helpful at a glance to ... have a ballpark idea. . . I mean, you could see a test in their folders and you have no idea what they are trying to tell you because of the kind of test. (T-J)

When we checked with Julia to clarify our understanding of her comment, she noted further, "Information that is helpful three to four months into the year is mostly applicable to [those] special needs students who have not made normal gains in any given time period" (T-J). 
Finally, Robert noted as a strength the alignment of the assessment with the state core objectives. He commented, "I think a strength is the fact that the testing or the assessment program is correlated to the standards and objectives that should be taught in the core curriculum" (A-R).

Weaknesses. While being able to garner some information at a glance was identified as a strength, others cited the narrow extent of that information as a weakness and noted that more information could be obtained through observation. In addition, some felt that the assessment lacked validity and that there is potential for placing undue importance on it. Finally, some suggested that the assessment did not result in changes in the curriculum.

The limited extent of the information gained from the assessment was a theme that emerged across groups. Robert felt that teachers could get virtually the same kind of information by administering "a combination of their own questions and the Brigance" (A-R). Others suggested that a test cannot tell "you what you know if you observe them" (T-P) and that "hands-on" activities (T-B) provide more information. Betty, a teacher, noted, "You can see right off how children sit in a circle time. Are they ready to watch as you read a book?" (TB). Kevin shared what teachers in his school had done in the past:

at our school, to find out the same kind of information, our teachers would have their kids in groups that they work in and the way they work in kindergarten and have a checklist in their hand on a clipboard. They would just check them off and they would have the indicators of each one of those skills. Kindergarten ... is the interaction with other kids and a lot of things that we can't put on paper/pencil [assessment]. (A-K)

\section{Bob elaborated on this position:}

Play is definitely a child's work. I think we could learn a lot more by putting children in a play environment; just sitting there with them and talking and listening and sharing. That's not part of the instrument" (A-B).

He later added, "Teachers are saying to me, we know after the first two weeks of regular school what ... we glean from this assessment" (A-B).

Lois felt that she wanted to create her own assessment in order to have the extent of information she needed:

because it was just reading and math, and that sure is not a kindergarten day. We do a lot more than that. ... I would like guidelines and some suggestions for assessment but eventually, I think I want a ['Lois Emmery'] assessment that I feel comfortable giving and reflects what I think is important. (T-L)

Julia said, "We added a few things at the end of the test" (T-J) while Robbie wanted more information on the test, particularly in terms of "social and emotional" development (T-R).

Recall that one purpose of the assessment was to provide information to the parents, so that they could support their children's literacy learning at home. Some parents, however, said they did not learn anything new about their child. Anna said, "The things they told me [my child] knew, I already knew she knew those things" (PA). Not allowed to be present during the administration of the assessment, Anna also pointed out that there was no immediate feedback to parents about the child's skills. "[The teacher] just said, 'She did a good job.' That was really it” (P-A).

Another shortcoming of the assessment was in identifying the literacy skills of developmentally advanced children, a concern mentioned by two parents, Mick and Sally. Mick noted, "The instrument was interested only in finding out what can this child can do within certain minimal parameters" and "It was fairly disappointing that the test never found out from the student what they could do" (P-M). Sally suggested, "There was a definite ceiling effect to the task, and so there was no way for [the teacher] to know what he could do" (P-S). Providing an example, Mick continued, 
[My son] brought his Ladybug magazine. He wanted to read it to his new teacher to show her that he could read. Well, there was no opportunity for that because the test doesn't want to know whether he can read going into kindergarten. It doesn't want to find out what he can do in the way of literacy. (P-M)

The accuracy of the assessment was cited as a weakness in terms of consistency of children's behaviors and the appropriateness of the assessment itself. Teacher Priscilla observed, "The children that acted up [during the assessment] didn't [do so] during the regular year, and those I had a few problems with [during the year] didn't show up during the assessment" (T-P). It was also noted that the format of the assessment might affect children's responses. For example, children were asked to identify letters, and Robbie felt that they might perform differently if the letters appeared "in a different font" (T-R). In addition, she noted,

On rhyming words and those things, the test was worded in such a way that I thought a lot of the kids were confused [about] what does a rhyming word mean. ... We felt there was vocabulary in it that was unfamiliar to the children and questions that were back-to-back that were really confusing, like "Choose the picture that begins with such and such." Right after that, we had to do, "What picture rhymes with such and such." It was really hard for kids.... The vocabulary in the test is so unfamiliar to them, especially if they are an ESL child. (T-R)

Administrators cited the potential for parents or teachers to assign undue importance to the assessment as a weakness. Bob's concern was that parents would "see what's going on there and say okay, that's what is valued and that's what is important" (A-B), while Hazel noted that teachers would get the message that such activities as "directed play ... the whole body experience" should consume less time in the classroom (A-H).

Placing undue importance on the assessment also might lead to inappropriate practices, such as academic redshirting or retention. Robert noted a concern "that those results, as valid and reliable as they are from a narrow perspective, may be used to tell parents that [their child] is not ready for kindergarten-that they need to be retained" (A-R). Kevin elaborated,

when we consider the data that we get from this, we can't use it to make gigantic decisions about students or instruction. It only tells us a narrow piece of where we are. .. . That's my biggest fear. This information is going to be used to make some pretty heavy decisions. (A-K)

While one purpose of the assessment was to inform instructional planning, it seems possible that the results were not always used for that purpose. "What I've heard from a lot of teachers," said Priscilla, "is that they're not really changing much what they're doing even after doing the assessment"(T-P). Similarly, parent Donna did not feel the assessment was beneficial to the children, noting, "it didn't help [the children]. They took the assessment; they went to school" (P-D).

\section{Time}

Strengths. Recall that the assessment took place during the first two weeks of school, when kindergarten classes were not held, so that the parents could bring their children to school at an appointed time to complete the assessment. School personnel cited this schedule as a strength because, "Teachers have adequate time to meet with the parent and the child in a 45 -minute block during the first two weeks of school" (A-R). This initial time set aside for the assessment was seen as something "the children will never have again during the course of the school year to the degree that they have it during the session in which they respond to the instrument" (A-B), as well as "an opportunity during the school year to have one-on-one" (T-J). Other teachers concurred, noting "the time ... was valuable" (T-R), and "being able to meet the parents like this was really [valuable]" (TH). Priscilla said, "That's the good part of 
the test; you get to meet the child and the parents, and you're one-on-one for an hour" (T-P).

Parents valued the time, because it enabled "the rest of the school [to] get organized" before the kindergarten children started (P-T) and provided "the opportunity to meet with the teacher and talk with her a little bit" (P-D).

Weaknesses. Two issues, related to the category of time, emerged as weaknesses. First, some saw the delay as a misuse of instructional time, while others felt that the two-week delay presented a hardship to families, particularly those with older children, who started on the first calendar day of school.

Administrators and teachers felt the time given solely to implementing the assessment was a poor use of instructional time. It was viewed as "bad PR" (T-P), and as being "too test-driven at the expense of instructional time" (A-R). Priscilla elaborated, "Kindergarten is out so much, anyway, and then to say ... your child is going to be out even more!" (T-P).

Referring to the prior practice in his district of paying kindergarten teachers to complete their own assessments during the two days preceding the first calendar day of school, Richard continued,

[In our district] we got essentially the same kind of information in two days protecting the school year, so that kids got a full 180 days of instruction. If there's any relationship between academic engaged time and achievement, we've encroached on that with this assessment. ... We've got to be about the business of teaching. (A-R)

\section{Similarly, Kevin commented,}

For us, the weakness that I see is [that] the kindergarten teachers that I have want to be spending more time doing things at the beginning of the year that are class-building in nature, that are facilitating the development of their program. (A-K)

The following dialogue between Mick and Donna exemplifies the perspective of some parents regarding the weakness related to time:

Because [the children] had to do a test, they found they had to wait. (P-M)

I have an older child and when she went to school and her younger sister knew she was going to school, the two weeks to go, so to speak, got to be a little bit hard. ... Two weeks! They delayed school two weeks. (P-D)

Yeah, I thought that was foolish, too. (P-M)

Well-Being of Children, Parents, and Teachers

Strengths. The ease of the first day of class and the comfort level of the children on their first day of school emerged as the strengths in this category. In addition, parents participating in this study did not feel that the assessment process left their children feeling particularly stressed out.

Participation in the assessment led to a smoother first day of school for kindergarten children. Teachers felt the children were more relaxed, because they "had met us before" (T-R), and "knew where their cubby was, the bathroom was, where they hang up their things" (T-H). Priscilla noted there were not "as many crying children to leave mom" (T-P), and Lois felt this made "the first day better, definitely" (T-L). Betty compared her recent experience with prior experiences by noting, "I will never forget my first year here last year, because I had children just pulling things down off my wall that first week" (T-B).

No data were coded in this category for administrators; among the parents we interviewed, only Cari noted that her child exhibited stress. Sally did not feel that the experience "stressed [her son] out particularly" and she "wasn't worried about" the issue of labeling based on the assessment results (P-S). Anna concurred: "[My daughter] was turning 6 by the end of September so with her, she was advanced, anyway, because of her age. So I wasn't concerned that they would say 'keep her home a year"' (P-A). 
Weaknesses. Weaknesses emerging in the category well-being of children, parents, and teachers related to parents' anxiety, and to inappropriate practice possibly causing anxiety in children. In addition, teachers commented on their stress related to accountability, giving the test exactly as it was scripted, and finding the assessment process to be exhausting.

The teachers reported observing some anxious parents. Their perception was that parents "wondered if [their child was] going to pass or fail" (T-P), "[were] very tense that their child wasn't answering questions right" (T-H), or demonstrated feelings that "their child was on trial" (T-R). Heidi further noted that "some parents were afraid that I wasn't going to keep their child in school" (T-H).

Robbie was particularly concerned about parental stress, noting that "mom and dad are hyperventilating [thinking] 'Joey, you know the ABCs!' or 'You know that; we reviewed that at home!"' (T-R). She continued,

And then, as the parent would leave sometimes they would say, "Well, [my child] knows their ABCs at home." And so I felt like what are they going to say to the child once he leaves; that they didn't do well? (T-R)

Julia struggled with the appearance of the test results sheets when she talked with parents, because the sheets "seemed so short and formal. I'm trying to share with the parent something that looked like this (holding a result sheet), but not very friendly." She chose to address this issue by not showing the standardized results sheets, but rather putting "together our own assessment that covered those things and a few other things [to show parents]" (T-J). She "graphed out the [results]" (T-J) so she could "cover up any names" (T-J) and share the results with parents.

Anna was the only parent we interviewed who felt stressed about the assessment. In her case, parents were asked to wait in the hallway, which caused her to wonder, "What are you doing with my child in there that I can't see?" (P-A). She also worried about her child being inappropri- ately labeled. "I think I was more stressed than [my daughter] was because I was worried that she would be labeled right off the bat" (P-A). She later added, "I don't think labeling them in kindergarten is a good thing to do" (P-A).

It was also noted that children were anxious-"really kind of scared"(T-J). Betty elaborated on this opinion:

I personally would like to see [the children] come in for at least two weeks before we do any assessment whatsoever so that they feel comfortable within their surroundings, feel comfortable with me ... so that when we sit down ready to really go through assessment, whether it be the Brigance, whether it be the state, whatever is required ... so that we can feel comfortable. (T-B)

Lois tried to present a "friendly and open and loving manner" (T-L) when she administered the assessment to children in her class, but she observed that "a lot of kids [were] very timid, very shy, scared" (TL). She said some children would periodically ask, "Is that right; is that okay?" (T-L), which led to her concern that they "felt kind of pressured" (T-L). Hazel suspected that children were "nervous about coming to school anyway; they've just had their shots" (A-H). She felt that "if they had the opportunity to come, get in the school system, not be afraid of the teacher," that an assessment "two or three weeks later into the year [would result in] a huge difference" (A-H).

Kevin questioned the alignment of the assessment with appropriate practice, noting, "All of a sudden we're going to assess, and we haven't even talked about what we want or what we want our kids to be" (A-K). Bob worried that it would lead to the implementation of an academic kindergarten:

I think some of our teachers are looking at it saying, "My central mission now as a teacher is going to be to put another worksheet on the desk to get that child to know his phonics...." When you do that, you are putting this child at risk because you're sacrificing all these other experiences. (A-B) 
Weaknesses. Weaknesses emerging in the category well-being of children, parents, and teachers related to parents' anxiety, and to inappropriate practice possibly causing anxiety in children. In addition, teachers commented on their stress related to accountability, giving the test exactly as it was scripted, and finding the assessment process to be exhausting.

The teachers reported observing some anxious parents. Their perception was that parents "wondered if [their child was] going to pass or fail" (T-P), "[were] very tense that their child wasn't answering questions right" (T-H), or demonstrated feelings that "their child was on trial" (T-R). Heidi further noted that "some parents were afraid that I wasn't going to keep their child in school" (T-H).

Robbie was particularly concerned about parental stress, noting that "mom and dad are hyperventilating [thinking] 'Joey, you know the ABCs!' or 'You know that; we reviewed that at home!"' (T-R). She continued,

And then, as the parent would leave sometimes they would say, "Well, [my child] knows their ABCs at home." And so I felt like what are they going to say to the child once he leaves; that they didn't do well? (T-R)

Julia struggled with the appearance of the test results sheets when she talked with parents, because the sheets "seemed so short and formal. I'm trying to share with the parent something that looked like this (holding a result sheet), but not very friendly." She chose to address this issue by not showing the standardized results sheets, but rather putting "together our own assessment that covered those things and a few other things [to show parents]" (T-J). She "graphed out the [results]" (T-J) so she could "cover up any names" (T-J) and share the results with parents.

Anna was the only parent we interviewed who felt stressed about the assessment. In her case, parents were asked to wait in the hallway, which caused her to wonder, "What are you doing with my child in there that I can't see?" (P-A). She also worried about her child being inappropri- ately labeled. "I think I was more stressed than [my daughter] was because I was worried that she would be labeled right off the bat" (P-A). She later added, "I don't think labeling them in kindergarten is a good thing to do" (P-A).

It was also noted that children were anxious-"really kind of scared"(T-J). Betty elaborated on this opinion:

I personally would like to see [the children] come in for at least two weeks before we do any assessment whatsoever so that they feel comfortable within their surroundings, feel comfortable with me ... so that when we sit down ready to really go through assessment, whether it be the Brigance, whether it be the state, whatever is required ... so that we can feel comfortable. (T-B)

Lois tried to present a "friendly and open and loving manner" (T-L) when she administered the assessment to children in her class, but she observed that "a lot of kids [were] very timid, very shy, scared" (TL). She said some children would periodically ask, "Is that right; is that okay?" (T-L), which led to her concern that they "felt kind of pressured" (T-L). Hazel suspected that children were "nervous about coming to school anyway; they've just had their shots" (A-H). She felt that "if they had the opportunity to come, get in the school system, not be afraid of the teacher," that an assessment "two or three weeks later into the year [would result in] a huge difference" (A-H).

Kevin questioned the alignment of the assessment with appropriate practice, noting, "All of a sudden we're going to assess, and we haven't even talked about what we want or what we want our kids to be" (A-K). Bob worried that it would lead to the implementation of an academic kindergarten:

I think some of our teachers are looking at it saying, "My central mission now as a teacher is going to be to put another worksheet on the desk to get that child to know his phonics. ..." When you do that, you are putting this child at risk because you're sacrificing all these other experiences. (A-B) 
Another pattern that emerged was concern that the children did not understand the questions or "understand what [the assessment] was all about" (P-S), which led to wrong responses to questions. This issue particularly surfaced with regard to questions about rhyming words. Sally noted,

How often do children just sit and listen to a list of rhyming words? ... I thought that was useful information but the way it was presented, it was hard for me to pick the rhyming pair just because of the list form it was in. (P-S)

Cari's daughter was also confused about rhyming words:

When she got home, [my daughter] says, "Mom, I understood it different than what she wanted and I messed up. . . ." [My daughter] thought [the teacher] wanted her to rhyme the first letter, like if something was $B$, she wanted something else B. But [the teacher] wanted her to rhyme the whole word and she was, "I messed up! I messed up!” (P-C)

Finally, some teachers felt personal stress. Noting that the assessment included asking children to read a sentence, Robbie wondered if "everyone else in the world is teaching that but me" (T-R). She added, "teachers teach to the test in some ways. I think there's a fear factor" (T-R).

Helping children understand the questions led to concerns about affecting the results because "I said it differently than the text" (T-L). Others said that the assessment process was exhausting or overwhelming, noting, "I'm exhausted by the time we get all the scoring done" (T-B), and "can we remember, after testing 50 children, who was it that couldn't remember left and right!" (T-R).

\section{Discussion}

Identifying the literacy and numeric skills of children entering kindergarten, as a way to inform instructional planning and provide information to parents to supportlearning at home, are worthwhile goals. What becomes a challenge, however, is meeting these objectives in a way that is developmentally appropriate for children and useful to teachers and parents. The themes that emerged from the data expand our understanding of existing theory by illuminating the specific aspects of a standardized kindergarten entrance assessment that were perceived as strengths and weaknesses by the stakeholders.

To summarize, the perceived strengths of the assessment that emerged from this inquiry include: a) some immediate information at a glance; b) consistency of information with the core curriculum and across districts; c) time and opportunity for oneon-one interaction among teachers, parents, and children; d) time and opportunity to begin parent and teacher dialogues; and e) easing the transition to the first day of school. The perceived weaknesses of the assessment that emerged from these data include: a) the narrow scope of information gleaned; b) lack of validity of the results; c) the potential for placing undue importance on the assessment, resulting in inappropriate practice; d) limited changes in the curriculum; e) misuse of instructional time; and $f$ ) anxiety for teachers, parents, and children.

Existing theory suggests that teachers should plan instruction based on knowledge of children's development and their individual families, cultures, and contexts (Bredekamp \& Copple, 1997). Considering the nature of the young learner, early childhood scholars propose that assessment should be rooted in developmentally appropriate classroom activities whereby teachers assess via observation, and by using a variety of materials (Culbertson \& Jalongo, 1999; Murphy \& Baker, 1990; Puckett \& Black, 1994; Vukelich, 1997), consider development over time, and refrain from comparing children on a given day (Puckett \& Black, 1994).

Observing children as they engage in hands-on activities emerged as the preferred approach to assessment in kindergarten. Time to observe children and some immediate information were perceived as valuable characteristics of the assessment; 
yet, data were viewed as narrow in scope and, in some cases, incomplete or inaccurate. For example, children known to be competent in identifying letters and rhyming words responded incorrectly to questions in those areas. In addition, the information obtained from the assessment did not always reveal the extent of the children's capabilities or provide adequate information so that parents could work with their children at home. The test format was perceived to be confusing to children, and the subsequent classroom performance of some of the children was inconsistent with the test results.

A second theoretical point is that standardized assessment may lead to the development of a narrow academic curriculum (Puckett \& Black, 1994) and other inappropriate practices (Kamii \& Kamii, 1990). While the data do not suggest that a narrow academic kindergarten curriculum has become standard practice in Utah, concern for this potential did emerge from the data because this assessment might carry the message that a narrow academic curriculum is valued. The data also suggest concern for the practice of retention or the potential for inappropriately labeling children as unready.

A third theoretical underpinning for this inquiry is that assessment is costly in terms of time and money (Anderson, 1998; Puckett \& Black, 1994). The data do not suggest concerns about monetary cost, but some perceived the assessment as infringing on instructional time. Some teachers felt that the two weeks allotted for testing would be better used completing observations and anecdotally noting children's development, thus obtaining a broader picture of their capabilities.

Theory also suggests the potential for teachers, parents, and children to experience frustration over standardized testing in the early grades (Anderson, 1998; Fleege et al., 1993; Haladyna et al., 1998; Wodtke et al., 1989). In this case, teachers would have preferred giving the children time to become comfortable with the school environment first. In addition, these data sug- gest that some parents and children were anxious about doing well on the test and that inappropriate labeling was a concern.

Finally, the researchers suggest ways to maintain the strengths of kindergarten entrance assessment and circumvent the weaknesses, as identified in this study. First, the data suggest that teachers, parents, and administrators valued the time allotted for testing as a time to become acquainted. To meet this objective, time can be provided-either during the first days of kindergarten or immediately prior to the start of the school year-for children and their parents to come to school for an informal meeting. During this time, children can become familiar with the teacher and school environment, teachers and parents can begin an ongoing dialogue, and teachers can begin assessment via observation.

Second, the data suggest that teachers desire the initial information and the consistency across school districts that the assessment provides. To address this objective, guidelines for assessing children's general social, emotional, physical, and cognitive development might replace the standardized instrument. The guidelines should encompass conventional knowledge and widely held developmental benchmarks, and they might take the form of checklists and forms to facilitate anecdotal note-taking. Checklists and anecdotes are readily available, serve as a continuous and detailed record of children's progress, and can be shared easily with parents on a regular basis.

At times, it is easy to get so caught up in solving problems that we fail to consider the nature and needs of the young children in our schools. However, teacher educators, public school and state office personnel, and policymakers must continue to advocate best practice and work to support young children in our schools. This inquiry can be compiled with others as we continue to examine assessment in kindergarten that encompasses the best use of time and money in meeting the needs of children, teachers, and parents. 
yet, data were viewed as narrow in scope and, in some cases, incomplete or inaccurate. For example, children known to be competent in identifying letters and rhyming words responded incorrectly to questions in those areas. In addition, the information obtained from the assessment did not always reveal the extent of the children's capabilities or provide adequate information so that parents could work with their children at home. The test format was perceived to be confusing to children, and the subsequent classroom performance of some of the children was inconsistent with the test results.

A second theoretical point is that standardized assessment may lead to the development of a narrow academic curriculum (Puckett \& Black, 1994) and other inappropriate practices (Kamii \& Kamii, 1990). While the data do not suggest that a narrow academic kindergarten curriculum has become standard practice in Utah, concern for this potential did emerge from the data because this assessment might carry the message that a narrow academic curriculum is valued. The data also suggest concern for the practice of retention or the potential for inappropriately labeling children as unready.

A third theoretical underpinning for this inquiry is that assessment is costly in terms of time and money (Anderson, 1998; Puckett \& Black, 1994). The data do not suggest concerns about monetary cost, but some perceived the assessment as infringing on instructional time. Some teachers felt that the two weeks allotted for testing would be better used completing observations and anecdotally noting children's development, thus obtaining a broader picture of their capabilities.

Theory also suggests the potential for teachers, parents, and children to experience frustration over standardized testing in the early grades (Anderson, 1998; Fleege et al., 1993; Haladyna et al., 1998; Wodtke et al., 1989). In this case, teachers would have preferred giving the children time to become comfortable with the school environment first. In addition, these data sug- gest that some parents and children were anxious about doing well on the test and that inappropriate labeling was a concern.

Finally, the researchers suggest ways to maintain the strengths of kindergarten entrance assessment and circumvent the weaknesses, as identified in this study. First, the data suggest that teachers, parents, and administrators valued the time allotted for testing as a time to become acquainted. To meet this objective, time can be provided-either during the first days of kindergarten or immediately prior to the start of the school year-for children and their parents to come to school for an informal meeting. During this time, children can become familiar with the teacher and school environment, teachers and parents can begin an ongoing dialogue, and teachers can begin assessment via observation.

Second, the data suggest that teachers desire the initial information and the consistency across school districts that the assessment provides. To address this objective, guidelines for assessing children's general social, emotional, physical, and cognitive development might replace the standardized instrument. The guidelines should encompass conventional knowledge and widely held developmental benchmarks, and they might take the form of checklists and forms to facilitate anecdotal note-taking. Checklists and anecdotes are readily available, serve as a continuous and detailed record of children's progress, and can be shared easily with parents on a regular basis.

At times, it is easy to get so caught up in solving problems that we fail to consider the nature and needs of the young children in our schools. However, teacher educators, public school and state office personnel, and policymakers must continue to advocate best practice and work to support young children in our schools. This inquiry can be compiled with others as we continue to examine assessment in kindergarten that encompasses the best use of time and money in meeting the needs of children, teachers, and parents. 


\section{References}

Anderson, S. R. (1998). The trouble with testing. Young Children, 54(4), 25-29.

Bogdan, R. C., \& Biklen, S. K. (1998). Qualitative research for education: An introduction to theory and methods. Boston: Allyn and Bacon.

Bredekamp, S., \& Copple, C. (Eds.). (1997). Developmentally appropriate practice in early childhood programs (Rev. ed.). Washington, DC: National Association for the Education of Young Children.

Burts, D. C., Hart, C. H., Charlesworth, R., \& Kirk, L. (1990). A comparison of frequencies of stress behaviors observed in kindergarten children in classrooms with developmentally appropriate versus developmentally inappropriate instructional practices. Early Childhood Research Quarterly, 5, 407423.

Culbertson, L. D., \& Jalongo, M. R. (1999). "But what's wrong with letter grades?”: Responding to parents' questions about alternative assessment. Childhood Education, 75, 130-135.

Fleege, P. O., Charlesworth, R., Burts, D. C., \& Hart, C. H. (1993). Stress begins in kindergarten: A look at behavior during standardized testing. Journal of Research in Childhood Education, 7(1), 20-26.

Haladyna, R., Haas, N., \& Allison, J. (1998). Continuing tensions in standardized testing. Childhood Education, 74, 262-273.

Kamii, C., \& Kamii, M. (1990). Why achievement testing should stop. In C. Kamii (Ed.), Achievement testing in the early grades: The games grown-ups play (pp. 15-38). Washington, DC: National Association for the Education of Young Children.

Lincoln, Y. S., \& Guba, E. G. (1985). Naturalistic inquiry. Newbury Park, CA: Sage Publications.

Meisels, S. J., Liaw, F., Dorfman, A., \& Nelson, R. F. (1995). The Work Sampling System: Reliability and validity of a performance assessment for young children. Early Childhood Research Quarterly, 10, 277-296.

Meisels, S. J. (1993). Remaking classroom assessment with the Work Sampling System. Young Children, 48(5), 34-40.

Morgan, D. L., \& Krueger, R. A. (1993). When to use focus groups and why. In D. L. Morgan (Ed.), Successful focus groups: Advancing the state of the art (pp. 3-19). Newbury Park, CA: Sage Publications.

Murphy, D., \& Baker, O. (1990). The approach of a state department. In C. Kamii (Ed.), Achievement testing in the early grades: The games grown-ups play (pp. 101-110). Washington, DC: National Association for the Education of Young Children.

Perrone, V. (1990). How did we get here? In C. Kamii (Ed.), Achievement testing in the early grades: The games grown-ups play (pp. 1-13). Washington, DC: National Association for the Education of Young Children.

Puckett, M. B., \& Black, J. K. (1994). Authentic assessment of the young child: Celebrating development and learning. New York: Macmillan
College Publishing Company.

Shepard, L., Kagan, S. L., \& Wurtz, E. (Eds.). (1998). Principles and recommendations for early child-hood assessmeints. Washington, DC: National Education Goals Panel.

Shepard, L. A., \& Smith, M. L. (1986). Synthesis of research on school readiness and kindergarten retention. Educational Leadership, 44(3), 78-86.

Shepard, L. A., \& Smith, M. L. (1988). Escalating academic demand in kindergarten: Counterproductive policies. The Elementary School Journal, 89(2), 135-144.

U.S. Bureau of the Census. (1999, September). States ranked by White population in 1998. Washington, DC: Author.

Vukelich, C. (1997). Assessing young children's literacy: Documenting growth and informing practice. In Billie Enz (Ed.), The Reading Teacher, 50(5), 430-434.

Wodtke, K. H., Harper, F., Schommer, M., \& Brunelli, P. (1989). How standardized is school testing? An exploratory observational study of standardized group testing in kindergarten. Educational Evaluation and Policy Analysis, 2, 223-235. 